\title{
The Cartagena Protocol on Biosafety's Negotiations: Science-policy Interface in GMO Risk
}

\author{
Angelika Hilbeck ${ }^{1}$ and Ossama A. El-Kawy²*
}

${ }^{1}$ Swiss Federal Institute of Technology, Institute of Integrative Biology, Zurich, Switzerland ${ }^{2}$ Atomic Energy Authority, Cairo, Egypt

\begin{abstract}
Since 2011, a scientific Guidance document on risk assessment of living modified organisms (LMO) has been developed in support of the Cartagena Protocol on Biosafety, an international treaty governing the trans boundary movement, transit, handling and use of LMOs by an inclusive process adhering to highest scientific standards (hundreds of experts, numerous online forums, face-to-face meetings, peer-reviews, revisions and testing rounds), in line with UN rules for inclusiveness (regional representation, gender) and grounded in scientific evidence (500 publications cited). We report how statements by a handful of Parties in line with counseling non-Parties discrediting the scientific basis of the Guidance without any scientific justification could repeatedly block progress through 'scientific filibustering' by sending the Guidance into endless testing and revision rounds with no sign of ever being willing to accept any Guidance document other than its abolishment. This will erode the basis of independent scientific expertise and undermine the legitimacy of this UN process most urgently needed by many developing countries.
\end{abstract}

Keywords: Risk assessment; Genetically modified organisms; Cartagena protocol on biosafety; International biosafety negotiation

\section{Introduction}

The Cartagena Protocol on Biosafety (CPB) is an international treaty governing the transboundary movement, transit, handling and use of living modified organisms (LMOs). It was adopted as a supplementary agreement to the Convention on Biological Diversity (CBD) and entered into force on 11 September 2003. The protocol aims to ensure an adequate level of protection from potential adverse effects of LMOs on the conservation and sustainable use of biological diversity, taking also into account risks to human health. It establishes an advance informed agreement (AIA) procedure before transboundary movement of LMOs, including a scientific risk assessment. There are now 168 Parties to this Protocol.

Few weeks ago, the Seventh Conference of the Parties serving as the Meeting of the Parties (COP-MOP7) to the Cartagena Protocol on Biosafety experienced a worrisome 'lowlight' of a development that has been mounting for a number of years, and that raises concerns about the science-policy interface and how it can be misused to serve vested interests. Scrapping the COP/MOP's work on risk assessment by business-friendly delegates would come close to dismantling the Protocol as a whole.

\section{Risk Assessment Negotiations}

All Parties to the CPB have always been unified in their call for robust science serving as foundation for crucial parts of the CPB. At its fourth meeting, Parties decided to establish an Ad Hoc Technical Expert Group (AHTEG) and an Open-ended Online Forum (OEOF) to address the need for further guidance on specific aspects of risk assessment and risk management [1]. 315 scientific experts are registered to the OEOF (213 nominated by Parties, 20 nominated by other governments and 82 by organizations). Members of the AHTEG were selected by the CBD Secretariat, in consultation with the COPMOP Bureau, from among those nominated experts on the basis of their expertise, and their active participation in the OEOF, taking into account geographic distribution and gender balance. The selection was also in accordance with the modus operandi of the Subsidiary Body on
Scientific, Technical and Technological Advice of the CBD. The first AHTEG (2008-2012) was composed of 18 experts from Parties and 9 Observers [2].

In accordance with its mandate [1,3], the first AHTEG, with the help of the larger OEOF, has developed, updated and improved the "Guidance on Risk Assessment of Living Modified Organisms". Huge efforts have also been made in terms of the citation of approximately 500 background scientific documents, such as peer-reviewed articles, referenced along the text of the document. The Guidance comprises a "Roadmap for Risk Assessment of Living Modified Organisms", four guidance documents on specific types of LMOs and traits and guidance on monitoring of LMOs released into the environment. These documents were always submitted to the larger online group of experts for revision and were subject to several testing processes followed again by revisions for improvements.

At COP-MOP 6, many delegates supported endorsing the Guidance. They felt that since it went through an extensive review through online forums and the AHTEG on risk assessment, the Guidance should be sufficiently mature to be endorsed by the COP-MOP as an essential resource for the development of nationally adapted risk assessment approaches [4]. At that time, and after four years, the document had been subject to 10 online discussion forums, 3 series of regional online conferences and 6 face to face meetings of the AHTEG and its subworking groups [5]. The document was also subject to extensive testing and scientific review processes, of which we mention:

1) A scientific review (February-March 2011) with a total of 33

${ }^{*}$ Corresponding author: Ossama A. El- Kawy, Atomic Energy Authority, Cairo-11787, Egypt, Tel: +201111561456; E-mail: elkawyo@gmail.com

Received February 25, 2015; Accepted February 27, 2015; Published February 28,2015

Citation: Hilbeck A, El-Kawy OA (2015) The Cartagena Protocol on Biosafety's Negotiations: Science-policy Interface in GMO Risk. J Health Edu Res Dev 3: e120. doi:10.4172/2380-5439.1000e120

Copyright: ( 2015 Hilbeck A, et al. This is an open-access article distributed under the terms of the Creative Commons Attribution License, which permits unrestricted use, distribution, and reproduction in any medium, provided the original author and source are credited. 
submissions (18 from Parties, three from other Governments and 12 from organizations) [6].

2) Testing of the Guidance (November-December 2011) with a total of 28 submissions made (23 from Parties, one from another Government and four from organizations) [7].

3) Two online forums held to share experiences with the testing $(23$ November-14 December 2009 and 28 November-3 December 2011) $[8,9]$

4) Scientific editing by an external consultant (March 2012).

5) Testing conducted during the regional training courses on risk assessment held by the secretariat [10-12]. It is worth mentioning that all those different testing processes were in favor of the Guidance and were followed by further revision and improvements.

However, despite numerous references emphasizing the voluntary nature of the Guidance and the broad understanding that it is a living document that would be tested and further revised, bearing in mind the continuously evolving nature of this field of science, a few delegates were adamant in refusing to endorse and operationalize the Guidance and were against the development of new guidance documents [4].

Due to this blocking, the COP-MOP 6 decided to call for another round of improvements by requesting a structured approach to testing and subsequent revision of the Guidance, and to bring to a close the current AHTEG and establish a new AHTEG, with no mandate to develop new guidance on risk assessment but rather to make "recommendation on how to proceed with respect to the development of further guidance on specific topics of risk assessment, selected on the basis of the priorities and needs indicated by the Parties with the view of moving toward the operational objectives 1.3 and 1.4 of the Strategic Plan and its outcomes" [13]. The second AHTEG (20122014) was composed of 15 experts from Parties and 9 Observers and its composition also took into account the need to balance past and new members [14].

The CBD Secretariat, with the help of the new AHTEG, structured and focused the process of testing the Guidance. The Guidance was tested with regards to practicality, usefulness, consistency with the Cartagena Protocol and taking into account past and present experiences. A total of 56 submissions were made on the results of the testing of the guidance from 43 parties, 3 other governments and 10 organizations. The analysis of the testing [15] showed overwhelming support for the Guidance, particularly from developing countries, and the new AHTEG recommended using the guidance document in its current form [14].

During COP-MOP7, most delegates expected to endorse the draft Guidance on risk assessment, allowing the COP-MOP to focus more work on further guidance for specific types of LMOs. Yet, the Guidance came under heavy attack by a handful of Parties calling it "counterproductive" and "unscientific" without offering any scientific reasoning or scientific evidence in support of their statements [16]. Then they requested that the COP-MOP discard the draft Guidance and stop the established process of developing it further through the AHTEG. They even went further to question the credentials and qualifications of the newly selected AHTEG who recommended the Guidance document to be used in its current version and asked for 'a fresh look at the Guidance', a thinly disguised attempt at convincing the COP-MOP to appoint to the AHTEG only those experts who would be in line with their preconceived minority views which are, curiously close to a few non-Parties who also happen to be the largest developers and exporters of GMOs.

Consequently, parties, again, could only agree on 'welcoming' the Guidance on risk assessment and inviting Parties, other Governments and relevant organizations, to further test or use, as appropriate, the Guidance. The use of such legally weak jargon, like welcomes and invites, undermines governments needing guidance to establish and practice quality risk assessment to meet their obligations under the Protocol, particularly developing country governments who find the Guidance so useful. This was celebrated as a success by the handful of Parties and their consulting non-Parties and observers who may now continue obstructing progress through a sort of 'scientific filibustering' by continuing to ask for further testing and revisions, yet show no sign of possibly ever being satisfied by any guidance on the matter other than its abolishment.

\section{Discussion}

The Cartagena Protocol is the only international treaty setting minimal agreed rules for the safety assessment of products such as living GMOs and their potential adverse effects on biodiversity, taking into account risks to human health, and is for many developing countries the only legal guidance for their domestic biosafety regulations of GMOs and the only mechanism granting them legal authority for holding developers and importers accountable for potential adverse effects resulting from transboundary movement and introduction of GMOs in their countries. Although the outcomes of this process as described above are weak and unsatisfactory, it remains an important first step: Parties are invited to start using the Guidance, which is a useful tool for risk assessment.

We understand that UN negotiations are largely political negotiations. However, good science needs to lead to good policies. We feel compelled to inform the public and the science community, from which experts to these processes are recruited, that in this particular process, their delivered science informed the negotiations through an unchecked political filter that allowed the distortion and dismissal of the science without scientific substantiation and justification of any kind, simply because the outcome did not fit a particular political or economic agenda. The process is disappointing to scientists who deal in the exchange of views on evidence rather than political tactics.

In the case we report here, the manipulative politics of a minority blunted progress on meeting the needs of those countries that see themselves as most in need of guidance on risk assessment. Undoubtedly, the clear prospect for an unfettered continuation of this state of affairs may already now lead to an erosion of the basis of independent scientific expertise and, thus, reward and reinforce such strategies of obstructing scientific progress in biosafety and risk assessment for the interest of the global public.

\section{References}

1. UNEP SCBD United Nations Environmental Programme Secretariat of the Convention on Biological Diversity (2008) BS-IV/11. Risk assessment and risk management,In Biosafety: Taking further steps towards effective implementation of the Protocol. Decisions of the Fourth Meeting of the Conference of the Parties to the Convention on Biological Diversity serving as the meeting of the Parties to the Cartagena Protocol on Biosafety, pp. 61-65.

2. UNEP SCBD United Nations Environmental Programme Secretariat of the Convention on Biological Diversity (2009a) The first meeting of the Ad Hoc Technical Expert Group on Risk Assessment and Risk Management under the Cartagena Protocol on Biosafety. Report No. UNEP/CBD/BS/AHTEGRA\&RM/1/3, Montreal, Canada.

3. UNEP SCBD United Nations Environmental Programme Secretariat of the 
Citation: Hilbeck A, El-Kawy OA (2015) The Cartagena Protocol on Biosafety's Negotiations: Science-policy Interface in GMO Risk. J Health Edu Res Dev 3: e120. doi:10.4172/2380-5439.1000e120

Page 3 of 3

Convention on Biological Diversity (2011a) BS-V/12. Risk assessment and risk management In Biosafety: Setting a new agenda, Decisions of the Fifth Meeting of the Conference of the Parties to the Convention on Biological Diversity Serving as the Meeting of the Parties to the Cartagena Protocol on Biosafety pp. 57-61.

4. Jungcurt (2012) Earth Negotiations Bulletin. lisd 9: 585.

5. UNEP SCBD United Nations Environmental Programme Secretariat of the Convention on Biological Diversity (2012a) Risk assessment and risk management Montreal, Canada.

6. UNEP SCBD United Nations Environmental Programme Secretariat of the Convention on Biological Diversity (2011b) Results of the scientific review of the Guidance on Risk Assessment of LMOs.

7. UNEP SCBD United Nations Environmental Programme Secretariat of the Convention on Biological Diversity (2011) Testing of the Guidance on Risk Assessment of LMOs.

8. UNEP SCBD United Nations Environmental Programme Secretariat of the Convention on Biological Diversity (2009b) Testing of the Roadmap for Risk Assessment.

9. UNEP SCBD United Nations Environmental Programme Secretariat of the Convention on Biological Diversity (2011) Exchange of experiences in the testing of the Guidance on Risk Assessment of LMOs.

10. UNEP SCBD United Nations Environmental Programme Secretariat of the Convention on Biological Diversity (2011e) Report of the Caribbean training course on Risk Assessment of Living Modified Organisms, Montreal, Canada.
11. UNEP SCBD United Nations Environmental Programme Secretariat of the Convention on Biological Diversity (2011f) Informe del curso latinoamericano de capacitación sobre laevaluación del riesgo de los organismos vivos modificados, Montreal, Canada.

12. UNEP SCBD United Nations Environmental Programme Secretariat of the Convention on Biological Diversity (2012) Report of the Anglophone Africa training course on Risk Assessment of Living Modified Organisms, Montreal, Canada.

13. UNEP SCBD United Nations Environmental Programme Secretariat of the Convention on Biological Diversity (2013) BS-VI/12. Risk assessment and risk management, In Biosafety: Tools to advance implementation. Decisions of the Sixth Meeting of the Conference of the Parties to the Convention on Biological Diversity serving as the meeting of the Parties to the Cartagena Protocol on Biosafety, pp. 69-74.

14. UNEP SCBD United Nations Environmental Programme Secretariat of the Convention on Biological Diversity (2014) Report of the ad Hoc Technical Expert group on Risk Assessment and Risk Management under the Cartagena Protocol on Biosafety, Montreal, Canada.

15. UNEP SCBD United Nations Environmental Programme Secretariat of the Convention on Biological Diversity (2014) Analysis of the results of the testing of the "Guidance on Risk Assessment of Living Modified Organisms, Montreal, Canada.

16. Antonich (2014) Earth Negotiations Bulletin.lisd 9: 635 